University of Nebraska - Lincoln

DigitalCommons@University of Nebraska - Lincoln

Publications, Agencies and Staff of the U.S.

Department of Commerce

U.S. Department of Commerce

2004

\title{
Maternal Age as a Determinant of Larval Growth and Survival in a Marine Fish, Sebastes Melanops
}

Steven A. Berkeley

Oregon State University, stevenab@cats.ucsc.edu

Colin Chapman

Oregon State University

Susan M. Sogard

National Marine Fisheries Service, susan.sogard@noaa.gov

Follow this and additional works at: https://digitalcommons.unl.edu/usdeptcommercepub

Berkeley, Steven A.; Chapman, Colin; and Sogard, Susan M., "Maternal Age as a Determinant of Larval Growth and Survival in a Marine Fish, Sebastes Melanops" (2004). Publications, Agencies and Staff of the U.S. Department of Commerce. 429.

https://digitalcommons.unl.edu/usdeptcommercepub/429

This Article is brought to you for free and open access by the U.S. Department of Commerce at DigitalCommons@University of Nebraska - Lincoln. It has been accepted for inclusion in Publications, Agencies and Staff of the U.S. Department of Commerce by an authorized administrator of DigitalCommons@University of Nebraska - Lincoln. 


\title{
MATERNAL AGE AS A DETERMINANT OF LARVAL GROWTH AND SURVIVAL IN A MARINE FISH, SEBASTES MELANOPS
}

\author{
Steven A. Berkeley,,$^{1,3}$ Colin Chapman, ${ }^{1,4}$ and Susan M. Sogard ${ }^{2}$
}

${ }^{1}$ Hatfield Marine Science Center, Oregon State University, Newport, Oregon 97365 USA

${ }^{2}$ National Marine Fisheries Service, 110 Shaffer Road, Santa Cruz, California 95060 USA

\begin{abstract}
Relative body size has long been recognized as a factor influencing reproductive success in fishes, but maternal age has only recently been considered. We monitored growth and starvation resistance in larvae from 20 female black rockfish (Sebastes melanops), ranging in age from five to 17 years. Larvae from the oldest females in our experiments had growth rates more than three times as fast and survived starvation more than twice as long as larvae from the youngest females. Female age was a far better predictor of larval performance than female size. The apparent underlying mechanism is a greater provisioning of larvae with energy-rich triacylglycerol (TAG) lipids as female age increases. The volume of the oil globule (composed primarily of TAG) present in larvae at parturition increases with maternal age and is correlated with subsequent growth and survival. These results suggest that progeny from older females can survive under a broader range of environmental conditions compared to progeny from younger females. Age truncation commonly induced by fisheries may, therefore, have severe consequences for long-term sustainability of fish populations.
\end{abstract}

Key words: larval quality; lipid allocation; maternal effects; reproductive trade-offs; Sebastes melanops.

\section{INTRODUCTION}

Many species of marine fish exhibit surprisingly long life spans, with the maximum age of species in a diverse range of families often exceeding 100 years (Cailliet et al. 2001). An association of longevity with variability in recruitment was initially documented for clupeiform fishes by Murphy (1968), and appears to be widespread in teleosts (Longhurst 2002). The adaptive value of a long life span is that reproductive output is allocated across many years, a bet-hedging strategy that ensures some reproductive success despite potentially long periods of environmental conditions unfavorable for larval survival (Leaman and Beamish 1984, Secor $2000 a$ ). At the population level, longevity provides a storage effect similar to the seed bank of plants, ensuring extended survival of adults until favorable recruitment conditions recur (Warner and Chesson 1985).

While the advantage of longevity for persistence of a population in a variable environment is intuitive, a growing body of evidence suggests that a broad age distribution can also reduce recruitment variability (Lambert 1990, Marteinsdottir and Thorarinsson 1998, Secor 2000b). There are at least two mechanisms by which this buffering could occur: (1) there may be age-

Manuscript received 23 October 2003; revised 27 October 2003; accepted 13 November 2003; final version received 4 December 2003. Corresponding Editor: M. A. Hixon.

${ }^{3}$ Present address: Long Marine Lab, University of California, 100 Shaffer Road, Santa Cruz, California 95060 USA. E-mail: stevenab@cats.ucsc.edu

${ }^{4}$ Present address: S.P. Cramer and Associates, Inc., 600 NW Fariss Road, Gresham, Oregon 97030 USA. related differences in the time and location of spawning (Lambert 1987, Hutchings and Myers 1993), effectively spreading larval production over temporally and spatially variable environmental conditions, and (2) older fish may produce more fit eggs and larvae (Hislop 1988, Marteinsdottir and Steinarsson 1998), which can survive under conditions inadequate for survival of progeny from younger fish. Theoretical analyses suggest that even slightly enhanced rates of early survival and growth have a cumulative effect that can translate into a greatly increased probability of subsequent recruitment (Houde 1987), and field studies have demonstrated a general trend of higher survival among faster growing individuals or cohorts during the larval stage (Meekan and Fortier 1996, Hare and Cowen 1997, Bergenius et al. 2002). Paradoxically, if older fish do produce larvae of better condition, thereby ensuring population viability, fishing obliterates this benefit by selectively removing larger, older individuals.

In this paper, we present results of rearing experiments that address the question of whether larval growth and survival rates are related to maternal age. Our study subject, black rockfish (Sebastes melanops), is a broadly distributed nearshore species in the northeast Pacific. The rockfishes in general are characterized by long life spans and slow adult growth compared to most other bony fishes, high recruitment variability, and a live-bearing reproductive pattern (Love et al. 2002). Females retain sperm in the lumen of the ovary for several months until the eggs are fertilized (usually December-February; Boehlert and Yoklavich 1984). Developing embryos receive nourishment from the fe- 


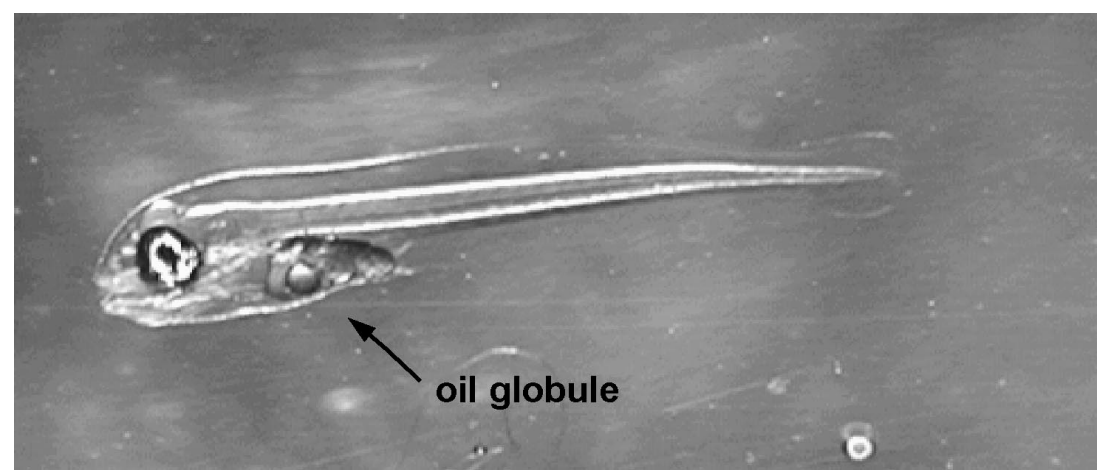

Plate 1. Newly extruded black rockfish larva $(\sim 4.6 \mathrm{~mm}$ notochord length) with oil globule clearly visible. Photo credit: Colin Chapman.

male and are thus considered viviparous (Yoklavich and Boehlert 1991). Following a gestation period of $\sim 37$ days at $10^{\circ} \mathrm{C}$ (Boehlert and Yoklavich 1984), females extrude 500000 to 1000000 larvae (S. J. Bobko and S. A. Berkeley, unpublished manuscript). Although this reproductive strategy provides maximum protection for progeny during the highly vulnerable egg and yolk-sac larval stages, at parturition the larvae are small ( $<5 \mathrm{~mm}$ in length), only five days posthatch (Yoklavich and Boehlert 1991), and only partially developed. Larvae are capable of feeding immediately after birth, but the period during which they can survive until adequate food becomes available is determined by the amount of endogenous energy stores at birth. Starvation during the initial feeding stage is thought to be a major source of larval mortality, contributing to fluctuations in year class strength (Lasker 1975), and may be a critical factor in recruitment variability in rockfishes (Moser and Boehlert 1991).

\section{Methods}

\section{Rearing experiments}

From 1998 to 2000, we collected mature female black rockfish along the central Oregon coast close to the time of larval parturition (December and January). Fish were held individually in 750-L tanks for 1-3 months without food in a flow-through seawater system at ambient temperatures (mean $=12^{\circ} \mathrm{C}$ ) and salinity. Larval development was monitored by anesthetizing the fish and withdrawing a sample of larvae using a catheter inserted into the oviduct. When parturition was imminent, we anesthetized the female and removed the larvae. Females were subsequently measured, weighed, and aged from their otoliths (MacLellan 1997). From fork length and wet mass (liver and ovaries removed) a condition index was calculated as (mass/length $\left.{ }^{3}\right) \times$ 100. A liver index was calculated as liver mass/wet mass, as a measure of energy reserves. A sample of $\sim 500$ larvae was rinsed in distilled water and frozen at $-80^{\circ} \mathrm{C}$ for proximate analysis of body composition. Carbon, nitrogen, and ash were determined using the Dumas combustion method (Analytical Chemistry Lab- oratory, University of California, Santa Barbara) and used to calculate protein and lipid concentration. Another sample of 40-50 larvae was photographed, with the images used to determine notochord length of individual larvae and the diameter of their oil globule (from which we calculated oil globule volume; see Plate 1). A separate sample of 10 larvae was rinsed in distilled water, dried at $60^{\circ} \mathrm{C}$ for $24 \mathrm{~h}$, and weighed to the nearest $1.0 \mu \mathrm{g}$ to estimate larval mass. Initial larval condition was calculated from the mean length and mass data of larvae collected from each female.

For the rearing experiments, we stocked 500 larvae in each of six 50-L tanks, with two replicates of three food densities $(0,1$, and 10 rotifers per $\mathrm{mL})$. We report here only the results of the 0 and 10 rotifer rations because there was no statistical difference between the two treatments receiving food. Larvae were reared at constant temperature $\left(10^{\circ} \mathrm{C}\right)$ under a $12: 12$, L:D photoperiod for 30 days or until all larvae had died. Growth rates were estimated from the fed tanks, based on a sample of 3-5 larvae removed every three days. Nitrate and ammonia levels were monitored every other day and remained below detectable levels.

Fed treatments received a diet of enriched marine rotifers (Brachionus plicatilis). Rotifer cultures were maintained on a combination of cultured live algae (Isochrysis galbana) and Rotimac (Aquafauna Biomarine, Hawthorne, California, USA), a commercial rotifer diet supplement. Prior to larval feeding, rotifers were enriched with Algamac 3010 flake enrichment medium (Aquafauna Bio-marine). Food levels in the rearing containers were monitored and adjusted daily to maintain target concentrations. Dead rotifers were siphoned daily from the bottom of the rearing tanks.

Growth in length and mass were estimated with linear regression models $L_{t}=a+b t$ and $\mathrm{W}_{t}=a+b t$, where $L_{t}$ is the estimated length $(\mathrm{mm})$ at time $t, W_{t}$ is the estimated dry mass $(\mathrm{mg})$ at time $t, b$ is the growth rate ( $\mathrm{mm}$ or $\mathrm{mg} / \mathrm{d}), t$ is time (d), and $a$ is the $y$-intercept. Growth in length and mass over the size range observed in these experiments was best described by a linear function. The slopes of these relationships were used

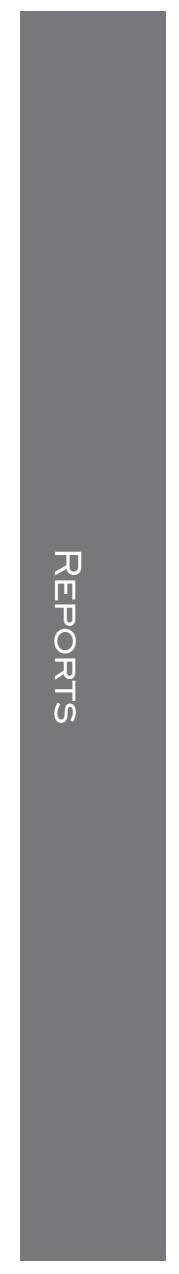


as dependent variables in subsequent regression analyses.

Time to starvation in the unfed treatments was estimated as the number of days until $50 \%$ of the initial number of larvae remained. Data for each measure of larval performance were pooled from the two replicates for each female.

\section{Age composition of wild populations}

We estimated the age structure of female black rockfish in wild populations by examining fish from recreational and commercial fishery catches off the coast of central Oregon in 1996-2000. Fishing effort was largely concentrated on nearshore rocky reef habitats $<60 \mathrm{~m}$ in depth. Most of our samples came from the discarded carcasses of recreationally caught fish. The majority of black rockfish we examined were either immature or male. All the mature females we encountered $(n=1643)$ were measured for length and aged from the otoliths. Ovary stage was determined and body condition was based on a liver index calculated as liver mass/length ${ }^{3}$.

\section{Data analysis}

Our hypothesis that larval performance is positively related to maternal age was tested using stepwise multiple regressions run separately for each measure of larval performance (growth in length, growth in mass, and time to $50 \%$ mortality). Maternal age, length, condition factor, and liver index were included as potential independent variables. All regressions were run as forward stepwise procedures, with criteria of $F=4.00$ for variable entry into the equation and $F=3.90$ for removal (SigmaStat version 2.03, SPSS, Chicago, Illinois, USA).

Results of these regressions were used to determine which measures of maternal fitness or condition are associated with larval performance. However, these measures do not provide insight into the mechanistic relationship between female condition and larval performance. Measured larval traits more directly affecting performance included larval condition index, initial larval length, initial percentage of lipids, and oil globule volume at parturition. We used stepwise multiple regression to test the influence of these independent variables on our three measures of larval performance (growth in length, growth in mass, and time to $50 \%$ mortality). A final stepwise regression examined the influence of maternal age, length, condition index, and liver index in determining oil globule volume. Best-fit simple regressions (linear and nonlinear) were fit to all measures of larval performance and all potential explanatory variables and maternal characteristics to allow a simple evaluation of significant relationships.

\section{RESULTS}

Effects of maternal traits on larval performance

Maternal age had a clear and striking effect on all three measures of larval performance. In the fed treat-

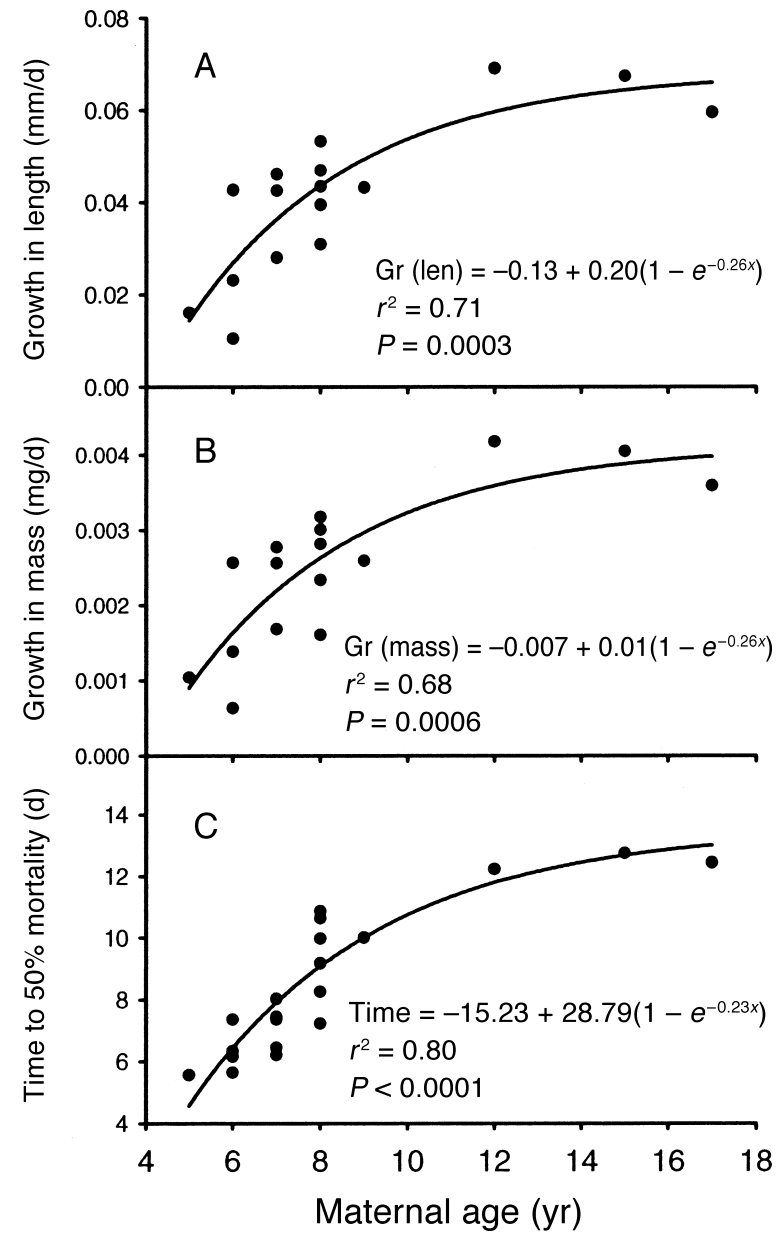

FIG. 1. Relationships in black rockfish between maternal age and (A) growth in length, (B) growth in mass, and (C) median time to starvation.

ments, larvae from the oldest females grew more than three times as fast in both length and mass as larvae from the youngest females (Fig. 1A, B). In the unfed treatments, larvae from the oldest females survived starvation more than twice as long as larvae from the youngest females (Fig. 1C). The three performance measures best fit an asymptotic relationship with maternal age, suggesting limited improvement in larval quality at maternal ages older than those in this study.

Although maternal age was strongly correlated with larval performance, stepwise multiple regressions determined whether other maternal traits potentially explained an additional proportion of the variance in performance (Appendix). These regressions were all highly significant (growth in length, $P=0.005$; growth in mass, $P=0.001$; survival, $P<0.001$ ), and maternal age explained most of the variability observed. Maternal age was the only significant predictor of growth in mass. Maternal length was also a significant independent variable in the regression of larval growth in length $(P=0.035)$, increasing the goodness of fit $\left(r^{2}\right)$ 
TABLE 1. Matrix of coefficients of determination $\left(r^{2}\right)$ for all larval and maternal traits measured in black rockfish.

\begin{tabular}{lccccccccccc}
\hline \hline & \multicolumn{10}{c}{ Trait } \\
\cline { 2 - 12 } Trait & GL & GW & S & ILL & LC & $\%$ L & OGV & MA & ML & MC & LI \\
\hline GL & & $* * *$ & 0 & 0 & 0 & 0 & $* * *$ & $* * *$ & $* *$ & 0 & 0 \\
GW & $\mathbf{0 . 9 9}$ & & 0 & $*$ & 0 & 0 & $* * *$ & $* * *$ & $*$ & 0 & 0 \\
S & 0.15 & 0.13 & & 0 & 0 & 0 & $* * *$ & $* * *$ & $*$ & 0 & 0 \\
ILL & 0.24 & $\mathbf{0 . 2 7}$ & 0.09 & & $* * *$ & 0 & 0 & $*$ & 0 & 0 & 0 \\
LC & 0.12 & 0.16 & 0.06 & $\mathbf{0 . 8 3}$ & & 0 & 0 & $*$ & 0 & 0 & $*$ \\
\%L & 0.00 & 0.00 & 0.01 & 0.01 & 0.02 & & 0 & 0 & 0 & 0 & $*$ \\
OGV & $\mathbf{0 . 5 9}$ & $\mathbf{0 . 5 6}$ & $\mathbf{0 . 8 2}$ & 0.15 & 0.07 & 0.15 & & $* * *$ & $*$ & 0 & 0 \\
MA & $\mathbf{0 . 7 1}$ & $\mathbf{0 . 6 8}$ & $\mathbf{0 . 8 0}$ & $\mathbf{0 . 2 9}$ & $\mathbf{0 . 2 1}$ & 0.00 & $\mathbf{0 . 8 2}$ & & $*$ & 0 & 0 \\
ML & $\mathbf{0 . 5 1}$ & $\mathbf{0 . 4 3}$ & $\mathbf{0 . 3 8}$ & 0.13 & 0.10 & 0.10 & $\mathbf{0 . 2 5}$ & $\mathbf{0 . 2 4}$ & & 0 & 0 \\
MC & 0.06 & 0.06 & 0.05 & 0.00 & 0.00 & 0.14 & 0.06 & 0.02 & 0.01 & & $* *(-)$ \\
LI & 0.15 & 0.16 & 0.06 & 0.12 & $\mathbf{0 . 2 1}$ & $\mathbf{0 . 2 6}$ & 0.01 & 0.10 & 0.07 & $\mathbf{0 . 4 2}$ & \\
\hline
\end{tabular}

Notes: Results are based on best fits of simple linear and nonlinear regressions between each pair of traits. Positive relationships are designated by asterisks and nonsignificant relationships $(P>0.05)$ by 0 . A negative relationship is designated with a minus sign (in parentheses). Coefficients of determination for significant regressions are shown in boldface type. Key to abbreviations: GL, larval growth rate in length; GW, larval growth rate in mass; S, time to 50\% mortality (survival); ILL, initial larval length; LC, larval condition at parturition; \%L, percentage of larval lipids; OGV, oil globule volume; MA, maternal age; ML, maternal length; MC, maternal condition; LI, liver index.

from 0.58 with only maternal age included to 0.71 with both variables included in the equation. In the regression of survival, maternal length was marginally significant $(P=0.055)$, and increased the goodness of fit from $r^{2}=0.67$ (including only maternal age) to 0.73 . This result suggests that females that are both old and large produce the highest quality larvae.

\section{Larval traits associated with larval performance}

The larval trait most highly correlated with larval performance was the volume of the oil globule present at parturition (Table 1, see also Plate 1). Similar to the relationship of maternal age with larval performance, larvae from cohorts with the largest oil globules at parturition had growth rates in both length and mass that were more than three times faster and survival rates more than twice as high as cohorts with the smallest oil globules (Fig. 2).

In all three multiple regressions evaluating larval performance with four indices of larval condition, oil globule volume was the only significant predictor of larval performance, explaining 55\%, 53\%, and 79\% of the observed variability in larval growth in length, growth in mass, and survival, respectively. Initial larval size, initial larval condition, and initial total larval lipids were all too weakly correlated with larval performance to be included in the regression equations (Appendix).

\section{Maternal traits and oil globule volume}

Maternal age was related to larval performance, and larval performance was related to oil globule volume at parturition, suggesting that oil globule volume was in turn a function of maternal age. The linear regression between oil globule volume and maternal age was highly significant $\left(r^{2}=0.82, P<0.001\right.$, Fig. 3$)$. A stepwise

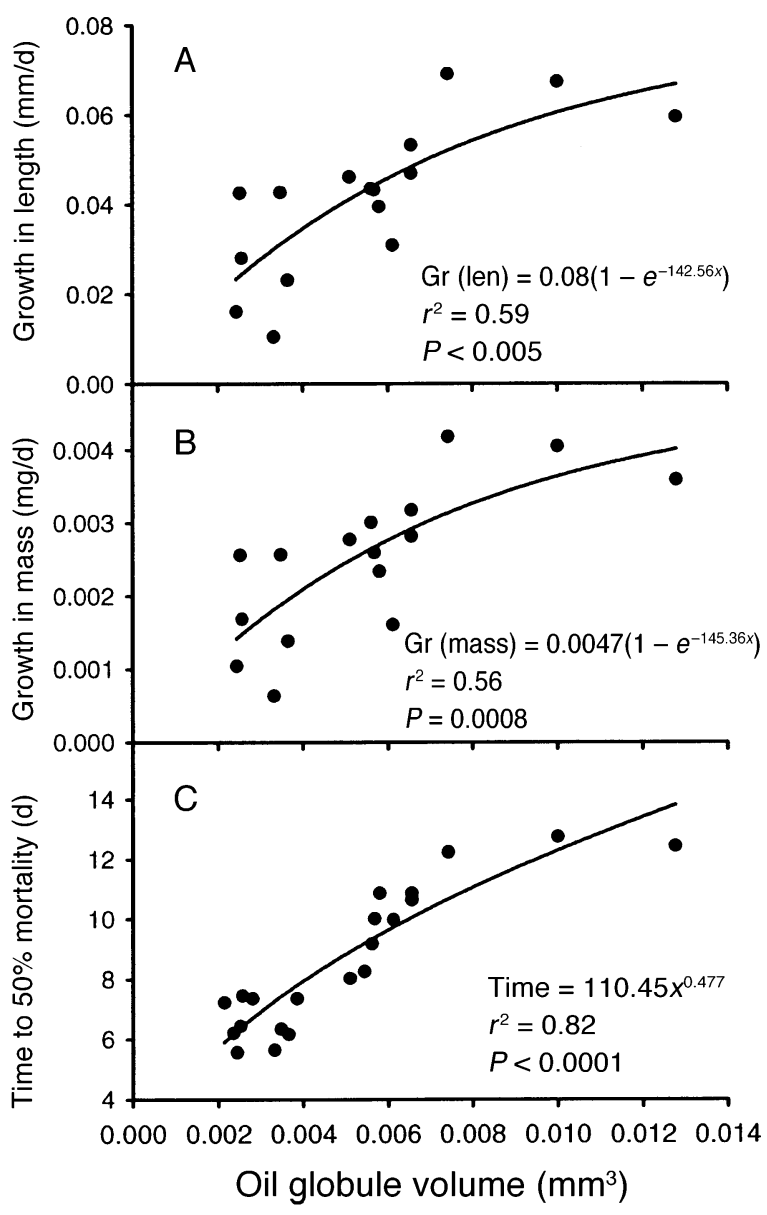

FIG. 2. Relationships in black rockfish between larval oil globule volume and (A) growth in length, (B) growth in mass, and $(\mathrm{C})$ median time to starvation. 


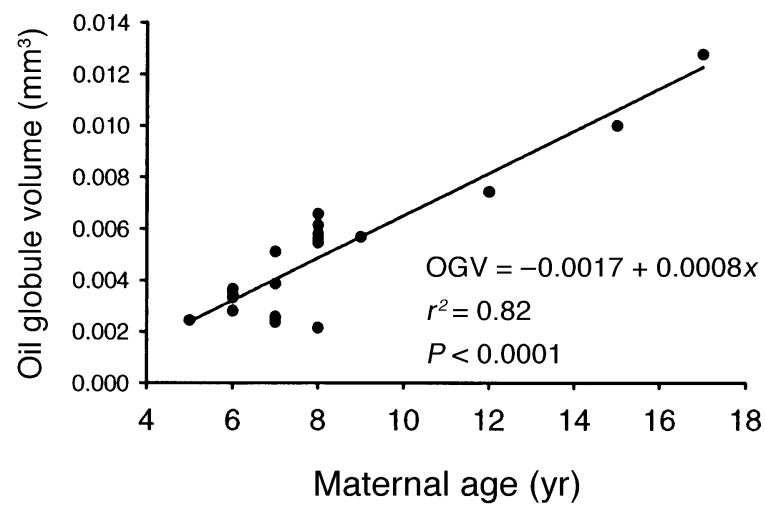

FIG. 3. Relationship between larval oil globule volume $(\mathrm{OGV})$ and maternal age in black rockfish.

multiple regression was used to evaluate potential contributions of additional maternal traits of length, condition, and liver index in determining oil globule volume (Appendix). Only the liver index was significant $(P=0.05)$, increasing the $r^{2}$ from 0.82 to 0.85 . However, the liver index was not related to maternal age (Table 1). To test for a laboratory effect on oil globule volume, we re-ran the multiple regression with time in captivity as an additional independent variable (Appendix). Although there was a weak negative correlation between time in captivity and age $\left(r^{2}=0.30\right)$ because parturition often occurs earlier in older fish, there was no additional explanatory power and time in captivity was not included in the final model $(P=$ 0.21). Our sample of wild females at comparable ovarian stages also did not exhibit any relation of liver index with age $(P=0.835)$, and they did not differ from our experimental fish (Mann Whitney $U$ test, $P=0.137$ ), suggesting that female condition was not influenced by our laboratory treatments.

\section{Evidence for age truncation in nature}

We observed a precipitous decline in the abundance of older age classes of black rockfish from 1996 to 1999 (Fig. 4). In 1996, the mean age of mature females retained by recreational fishermen in our sample was 9.3 years. By 2000, the mean age was only 7.4 years. There was no indication of a particularly abundant year class in the population that might have accounted for the decreased mean age of mature fish.

\section{DISCUSSION}

These results demonstrate a strong correspondence between maternal age and larval performance and indicate a likely mechanism for this relationship. Older black rockfish females provision their larvae with significantly larger oil globules than younger females, and the size of the oil globule appears to strongly affect larval growth and survival. At extrusion, most of the yolk has already been absorbed in rockfish larvae, but endogenous energy is available in the oil globule, which is primarily composed of triacylglycerol (TAG), the lipid fraction providing energy for metabolism and growth (Norton et al. 2001). The importance of measuring a direct index of TAG availability rather than total lipids is evident from the lack of correspondence of the latter with either growth or survival. High variability in oil globule volume at a given larval size is evident in other larval rockfish (Norton et al. 2001), suggesting a trait susceptible to selective mortality processes, although the role of maternal age in determining oil volume has not been previously reported. The oil globule is likely the major source of energy sustaining larvae during the difficult transition to exogenous feeding. The size of the oil globule has also been correlated with larval survival in capelin (Chambers et al. 1989), an unrelated species with a contrasting reproductive pattern of external fertilization and broadcast spawning. Our results for the unfed treatments revealed a close correspondence between available TAG and survival. For the fed larvae, enhanced growth rates of cohorts with larger oil globules at parturition suggested that greater stores of TAG provided important benefits even when ad libitum food was continually present.

It seems likely that such large differences in growth and starvation tolerance would have a profound effect on larval survival. The ability of larval fish to survive a period of starvation is often critical due to the spatial and temporal unpredictability of encountering patches of zooplankton prey (Hunter 1981). Fast growth has clear benefits in allowing larvae to pass more quickly through the most vulnerable life history stages and to develop faster in physical and physiological capabilities that improve detection and capture of prey, avoidance of predators, and resistance to environmental challenges (Fuiman and Cowan 2003). Field studies have demonstrated that relatively small differences in growth rate, especially in the youngest larvae, can have a profound effect on survival: a doubling of the growth rate in larval bluefish (Pomatomus saltatrix) and Atlantic cod (Gadus morhua) can increase survival by a factor of 5-10 (Meekan and Fortier 1996, Hare and

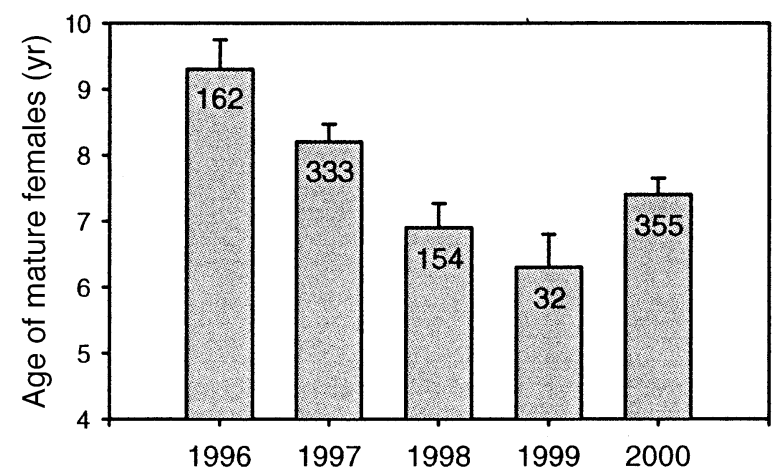

FIG. 4. Age (mean and $95 \% \mathrm{CI}$ ) of mature female black rockfish sampled off the central Oregon coast for five years. Sample size is shown inside bars. 
Cowen 1997). We observed increases in survival by nearly a factor of three and in growth by nearly a factor of four between the offspring of young and old black rockfish. These differences may be conservative since larvae were reared under constant environmental conditions, with ad libitum rations in fed treatments, and no exposure to predators or competitors (other than their siblings).

These findings have important ramifications for management of marine fish populations. Current management paradigms for a broad array of species assume that all larvae, regardless of parental age, have an equal probability of survival. Results of our experiments suggest that this assumption is not true for black rockfish. Comparable effects of maternal age on progeny quality are evident in haddock (Melanogrammus aegelfinus, Hislop 1988) and Atlantic cod (Marteinsdottir and Steinarsson 1998), unrelated species with very different reproductive strategies than the live-bearing rockfish we studied, suggesting a broad generality to such age effects. Age truncation induced by removing large fish via fishing can, therefore, have a much greater impact on the reproductive capacity of a population than the simple reduction in biomass of mature females. Maintaining a significant proportion of older fish may be critical to long-term replenishment and stability in exploited fish populations. Murawski et al. (2001) provide an elegant synthesis of these effects in Atlantic cod. Other studies have also concluded that the biomass of mature females without regard to their age structure may overestimate the production of viable larvae (Trippel et al. 1997, Scott et al. 1999, Vallin and Nissling 2000).

Age truncation in fished populations is a widespread problem. Our data on adult ages were derived from nearshore reefs on the coast of Oregon that received intensified recreational fishing pressure in conjunction with the decline and eventual prohibition of coho salmon recreational fishing during the 1990s. Port sampling data collected by the Oregon Department of Fish and Wildlife (unpublished data) indicate that groundfish catches by recreational fishermen doubled in the 1990s compared to the 1980s. Although this shift in fishing effort was highly localized and we have only a short time series, the rapid removal of older fish was particularly striking.

Although female size was correlated with all of our measures of larval performance, maternal age explained a much greater proportion of the variance. Female size was correlated with age, but the relationship was relatively weak. Like most long-lived fishes, postmaturation growth rates of black rockfish are slow. Thus, the improvement in larval quality with maternal age was likely due to factors other than an increase in body size. Maternal effects on progeny quality and performance have previously been associated with the female's health and condition (Chambers and Waiwood 1996, Kerrigan 1997), but a potential shift in allocation strategy with age has not been reported. Our indices of body and liver condition in females were derived from individuals postparturition (i.e., after exhaustion of maternal energy investment in reproduction), and revealed no correspondence with age. Assessment of female condition prior to egg fertilization will be needed to determine whether increased larval quality with increased age is a function of maternal energy reserves or some other trade-off in allocation. Increasing investment in larval TAG reserves with maternal age in black rockfish does not appear to be associated with a trade-off in fecundity. In fact, relative fecundity (number of larvae per gram of maternal body mass) increases with age (S. J. Bobko and S. A. Berkeley, unpublished manuscript). These age-related traits provide unequivocal support for the protection of older females in exploited fish populations.

\section{ACKNOWLEDGMENTS}

This research was funded by the NOAA Office of Sea Grant and Extramural Programs, U.S. Department of Commerce, under grant number NA76RG0476 (project numbers R/RCF01 and R/RCF-01-pd), and by appropriations made by the Oregon State legislature. The views expressed herein do not necessarily reflect the views of any of those organizations. We are grateful for the support of Oregon Sea Grant.

\section{Literature Cited}

Bergenius, M. A. J., M. G. Meekan, D. R. Robertson, and M. I. McCormick. 2002. Larval growth predicts the recruitment success of a coral reef fish. Oecologia 131:521525 .

Boehlert, G. W., and M. Yoklavich. 1984. Reproduction, embryonic energetics, and the maternal fetal relationship in the viviparous genus Sebastes (Pisces:Scorpaenidae). Biological Bulletin 167:354-370.

Cailliet, G. M., A. H. Andrews, E. J. Burton, D. L. Watters, D. E. Kline, and L. A. Ferry-Graham. 2001. Age determination and validation studies of marine fishes: do deepdwellers live longer? Experimental Gerontology 36:739764.

Chambers, R. C., W. C. Leggett, and J. A. Brown. 1989. Egg size, female effects, and the correlations between early life history traits: an appraisal at the individual level. Fishery Bulletin 87:515-523.

Chambers, R. C., and K. G. Waiwood. 1996. Maternal and seasonal differences in egg sizes and spawning characteristics of captive Atlantic cod (Gadus morhua). Canadian Journal of Fisheries and Aquatic Sciences 53:1986-2003.

Fuiman, L. A., and J. H. Cowan, Jr. 2003. Behavior and recruitment success in fish larvae: repeatability and covariation of survival skills. Ecology 84:53-67.

Hare, J. A., and R. K. Cowen. 1997. Size, growth, development and survival of the planktonic larvae of Pomatomus saltatrix (Pisces: Pomatomidae). Ecology 78:2415-2431.

Hislop, J. R. G. 1988. The influence of maternal length and age on the size and weight of the eggs and the relative fecundity of the haddock, Melanogrammus aeglefinus, in British waters. Journal of Fish Biology 32:923-930.

Houde, E. D. 1987. Fish early life dynamics and recruitment variability. American Fisheries Society Symposium 2:1729.

Hunter, J. R. 1981. Feeding ecology and predation of marine fish larvae. Pages 33-77 in R. Lasker, editor. Marine fish larvae. Washington Sea Grant, Seattle, Washington, USA.

Hutchings, J. A., and R. A. Myers. 1993. Effect of age on the seasonality of maturation and spawning of Atlantic cod,

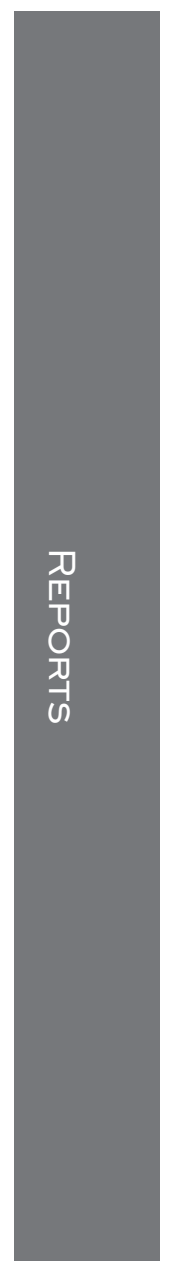


Gadus morhua, in the northwest Atlantic. Canadian Journal of Fisheries and Aquatic Sciences 50:2468-2474.

Kerrigan, B. A. 1997. Variability in larval development of the tropical reef fish Pomacentrus amboinensis (Pomacentridae): the parental legacy. Marine Biology 127:395-402.

Lambert, T. C. 1987. Duration and intensity of spawning in herring Clupea harengus as related to the age structure of the population. Marine Ecology Progress Series 39:209220 .

Lambert, T. C. 1990. The effect of population structure on recruitment in herring. Journal du Conseil International pour l'Exploration de la Mer 47:249-255.

Lasker, R. 1975. Field criteria for survival of anchovy larvae: the relation between inshore chlorophyll maximum layers and successful first feeding. Fishery Bulletin 73:453-462.

Leaman, B. M., and R. J. Beamish. 1984. Ecological and management implications of longevity in some northeast Pacific groundfishes. International North Pacific Fisheries Commission Bulletin 42:85-97.

Longhurst, A. 2002. Murphy's law revisited: longevity as a factor in recruitment to fish populations. Fisheries Research 56:125-131.

Love, M. S., M. Yoklavich, and L. Thorsteinson. 2002. The rockfishes of the Northeast Pacific. University of California Press, Berkeley, California, USA.

MacLellan, S. E. 1997. How to age rockfish (Sebastes) using S. alutus as an example-the otolith burnts (sic) section technique. Canadian technical report of fisheries and aquatic sciences. Canada Department of Fisheries and Oceans, Nanaimo, British Columbia, Canada.

Marteinsdottir, G., and A. Steinarsson. 1998. Maternal influence on the size and viability of cod (Gadus morhua L.) eggs and larvae. Journal of Fish Biology 52:1241-1258.

Marteinsdottir, G., and K. Thorarinsson. 1998. Improving the stock-recruitment relationship in Icelandic cod (Gadus morhua) by including age diversity of spawners. Canadian Journal of Fisheries and Aquatic Sciences 55:1372-1377.

Meekan, M. G., and L. Fortier. 1996. Selection for fast growth during the larval life of Atlantic cod Gadus morhua on the Scotian Shelf. Marine Ecology Progress Series 137:25-37.
Moser, H. G., and G. W. Boehlert. 1991. Ecology of pelagic larvae and juveniles of the genus Sebastes. Environmental Biology of Fishes 30:203-224.

Murawski, S. A., P. J. Rago, and E. A. Trippel. 2001. Impacts of demographic variation in spawning characteristics on reference points for fishery management. ICES Journal of Marine Science 58:1002-1014.

Murphy, G. I. 1968. Pattern in life history and the environment. American Naturalist 102:391-403.

Norton, E. C., R. B. MacFarlane, and M. S. Mohr. 2001. Lipid class dynamics during development in early life stages of shortbelly rockfish and their application to condition assessment. Journal of Fish Biology 58:1010-1024.

Scott, B., G. Marteinsdottir, and P. Wright. 1999. Potential effects of maternal factors on spawning stock-recruitment relationships under varying fishing pressure. Canadian Journal of Fisheries and Aquatic Sciences 56:1882-1890.

Secor, D. H. 2000a. Longevity and resilience of Chesapeake Bay striped bass. ICES Journal of Marine Science 57:808815.

Secor, D. H. 2000b. Spawning in the nick of time? Effect of adult demographics on spawning behavior and recruitment in Chesapeake Bay striped bass. ICES Journal of Marine Science 57:403-411.

Trippel, E. A., O. S. Kjesbu, and P. Solemdal. 1997. Effects of adult age and size structure on reproductive output in marine fishes. Pages 31-62 in R. C. Chambers and E. A. Trippel, editors. Early life history and recruitment in fish populations. Chapman and Hall, New York, New York, USA.

Vallin, L., and A. Nissling. 2000. Maternal effects on egg size and egg buoyancy of Baltic cod, Gadus morhua: implications for stock structure effects on recruitment. Fisheries Research 49:21-37.

Warner, R. R., and P. L. Chesson. 1985. Coexistence mediated by recruitment fluctuations: a field guide to the storage effect. American Naturalist 125:769-787.

Yoklavich, M., and G. W. Boehlert. 1991. Uptake and utilization of ${ }^{14} \mathrm{C}$-glycine by embryos of Sebastes melanops. Environmental Biology of Fishes 30:147-153.

\section{APPENDIX}

The results of all stepwise multiple regressions are available in ESA's Electronic Data Archive: Ecological Archives E085032-A1. 